\title{
Acoustic Detection of Intracranial Aneurysms: A Decision Analysis
}

\author{
A. C. van Bruggen ${ }^{1}$, D. W. J. Dippel ${ }^{2}$, J. D. F. Habbema ${ }^{3}$, and J. J. A. Mooij ${ }^{1}$ \\ ${ }^{1}$ Department of Neurosurgery, University Hospital Groningen, Groningen, ${ }^{2}$ Department of Neurology, University Hospital Dijkzigt. Rot- \\ terdam, and ${ }^{3}$ Centre for Clinical Decision Sciences, Department of Public Health, Erasmus University, Rotterdam, The Netherlands
}

\begin{abstract}
Summary
We present a further evaluation of an improved recording method for the acoustic detection of intracranial aneurysms (ADA). A sensor was applied to the patient's eyes. Two measures were derived to summarize the power spectral density functions of the sound frequencies that were obtained from each patient: the power median (PM), the median of the power spectral density function, and the mean difference error (MDE), a measure of the difference between the normalized, logarithmically transformed spectra of the patient and a template, the normal spectrum. The capability of these two measures (alone or combined) to discriminate between patients with and without an intracranial aneurysm was tested in a series of 89 patients harbouring a total of 109 aneurysms and 73 controls, using multiple logistic regression analysis. When PM and MDE were combined, the accuracy of the predictions amounted to $79 \%$. Individualized threshold values of the likelihood ratio of harbouring an aneurysm, for ordering four-vessel angiography are suggested, depending on the prior probability of harbouring an aneurysm, the risks of unnecessary angiography and the risk of living with an undetected aneurysm. Our decision analysis suggests that using these recommendations, employing acoustic detection results in a small gain in quality adjusted life expectancy ( 0.01 life year) for patients aged between 40 and 60, compared to no diagnostic testing, and 0.02 life year compared to angiography, which cannot be recommended. For patients with a three times increased prior risk of harbouring an intracranial aneurysm, the benefit of ADA compared to angiography increases to 0.05 life year. We conclude that acoustic detection has the potential of becoming a useful tool in the non-invasive diagnosis of occult, asymptomatic intracranial aneurysms.
\end{abstract}

Keywords: Intracranial aneurysm; non-invasive diagnosis; sound recording; decision analysis.

\section{Introduction}

Aneurysmal subarachnoid haemorrhage (SAH) occurs at a population rate of $1 / 10,000$ annually, with a mortality of more than $50 \%[2,11,23]$. Unruptured intracranial aneurysms are present in at least one per- cent of the general population, and they constitute a major risk to health $[18,38,39]$. Screening for unruptured intracranial aneurysms has been advocated or carried out in high risk groups, such as relatives of patients with SAH [4] and patients with autosomal dominant polycystic kidney disease [5, 37]. However, a convenient diagnostic procedure is not yet available for routine clinical use.

Angiography has a risk of complications and is expensive and time-consuming, because it is usually an in-hospital investigation. Not only should a screening strategy preferably be non-invasive, but it should also be reliable and accurate. High resolution CT scanning lacks sensitivity for smaller aneurysms [19, 27, 30], magnetic resonance imaging and magnetic resonance angiography have not yet been evaluated properly $[3,21,26]$, and both are expensive procedures.

It has long been known that aneurysms emit sounds, although early reports may actually have concerned bruits caused by vasospasm in patients with a ruptured aneurysm [25]. Later studies which made use of electronic stethoscopes suggested that the aneurysm itself generates vibration, probably because of turbulence of the aneurysmal blood flow. However, the sensitivity of such procedures seemed to be low, i.e., less than $50 \%[16,17,20,28,29]$. We present further results of the evaluation of an improved acoustic detection technique for intracranial aneurysms (ADA). We evaluated its diagnostic accuracy and analysed the clinical indications for its use with decision theory, taking into account the benefits of treatment of an unruptured aneurysm, and the risk of angiography and aneurysm surgery. 


\section{Methods and Patients}

\section{Patients}

Eighty-nine patients with a total of 104 aneurysms who were consecutively admitted to the neurosurgical department of the Groningen University Hospital with aneurysmal subarachnoid haemorrhage $(n=77)$, or with an unruptured aneurysm $(n=12)$ were evaluated with the acoustic detection technique. All aneurysms were confirmed by angiography. The control group consisted of 73 patients without known intracranial pathology: they were admitted to the clinic for spinal abnormalities: disc protrusion, spinal stenosis or carpal tunnel syndrome. The results on the first 26 controls and aneurysm patients have been published earlier [31], and another sample of these patients was used as controls in a study of patients with brain tumours [33].

\section{Acoustic Detection of Aneurysms}

Our procedure for the recording of intracranial sound has been described earlier [15, 31]. Briefly, microphones were placed over the closed eyes of each patient, using ultrasonic transmission gel (Fig. 1). The sound signals from the microphones were amplified and filtered (band pass $200-1250 \mathrm{~Hz}, 2$ nd order), and sent to a personal computer. An electrocardiogram signal was recorded simultaneously to obtain a trigger signal. A delay of $200 \mathrm{~ms}$ between trigger and sampling procedure was chosen, because the maximum blood-flow velocity, and therefore, the maximum sound amplitude in the intracranial vesseis occurs between 200 and $300 \mathrm{~ms}$ after the R-wave of the QRS-complex. With a real-time Fast Fourier Transform procedure the time series were transformed into power periodograms. Approximately 50 periodograms were obtained and averaged. The resulting power spectra (relative power spectral density as a function of the frequency), were shown from $200-1250 \mathrm{~Hz}$, and normalized to their maximum value. An automatic clipping technique was used for selectively removing loud signals such as from breathing, eye blinking or movement. One measuring cycle, consisting of sampling, FFT and averaging had a duration of $850 \mathrm{msec}$; the total diagnostic procedure took 10-15 minutes.
Two measures were used to summarize the power spectral density functions of the sound frequencies that were obtained from each patient. The first, the power median (PM), is the median of the power spectral density function: the frequency at which the area below the power spectrum on the left equals the area below the power spectrum on the right. The choice of this parameter was based on the observation in previous experiments that the medians of the spectra in normal patients were rather shifted to the left, whereas every disturbance of the smoothly descending curve results in a shift of the right. To obtain one parameter per measurement, the medians of the power spectra of the left and right eye were simply added. The second measure, the mean difference error (MDE), is a measure of the difference between two normalized, logarithmically transformed spectra: the patient's spectrum and a template, the normal spectrum. This normal spectrum was derived by averaging 9 spectra from independent control subjects, who were not included in the present study. To obtain one parameter per measurement, we took the mean of the MDE of the right and left eye.

\section{Statistical Analysis}

We used multiple logistic regression analysis to determine the discriminatory ability of the PM and MDE, alone and combined. In logistic regression analysis, the post-test odds $O_{p}$ of an aneurysm are expressed as:

$$
\log _{2}(O p)=\left(\beta_{0}+\beta_{1} v_{1}+\ldots+\beta_{i} v_{i}\right)
$$

where each term consists of the product of a regression coefficient $\beta$ and a parameter $v$ (for example the PM or the MDE). "For ease of interpretation, we used base 2 logarithms $\left(\log _{2}\right)$. Each point increase of the $\log _{2}$ odds doubles the posterior odds. ${ }^{*}$ Logistic

"Odds are defined as $O=p /(l-p)$, where $p$ stands for probability. In particular, odds of 1 correspond to a probability of $50 \%$. In order to go back from odds to probability, once calculates $p=O /(I+O)$.

*** In order to go from $\log _{2}$ odds to $\log _{\mathrm{e}}$ odds one computes: $\log _{e}(O)=\log _{2}(O) \times \log _{e}(2)=\log _{2}(O) \times 0.693$. output (example)

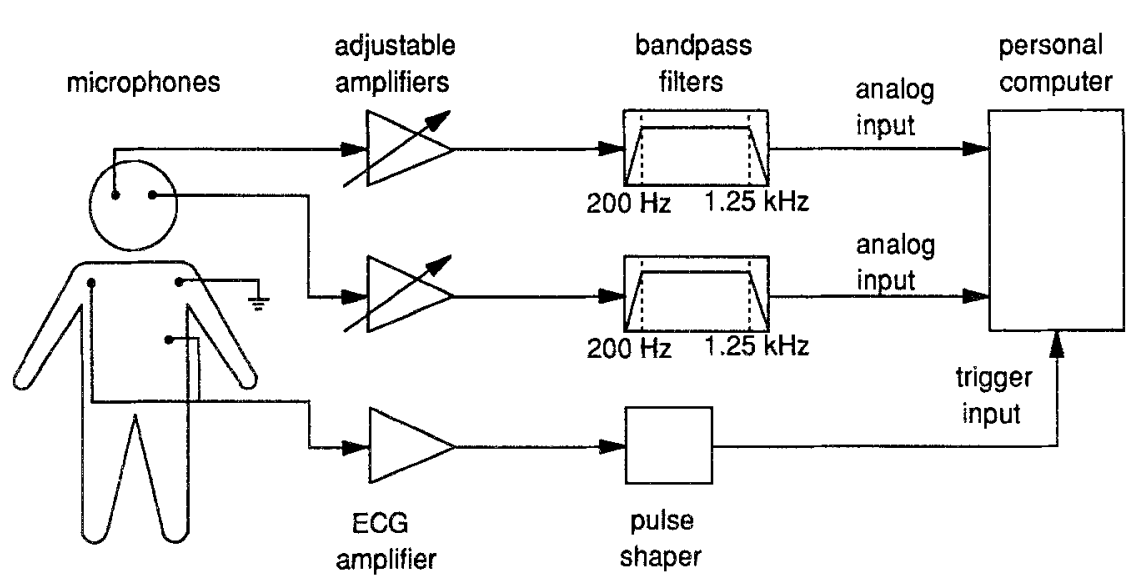

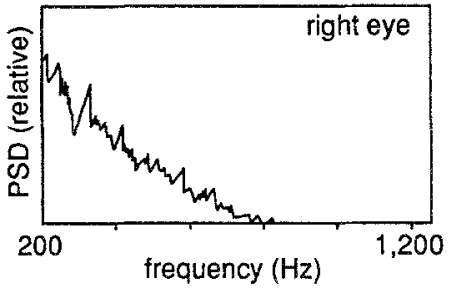

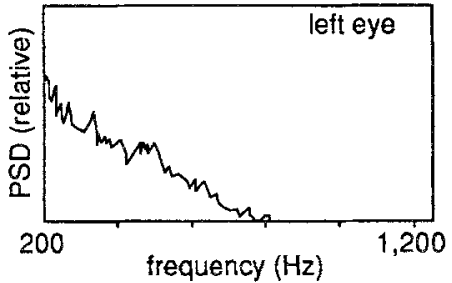

Fig. 1. Setup for the recording of intracranial sound. The sound signals, measured over the eyes, are amplitied, band filtered (200-1250) and sent to the computer. An electrocardiogram pulse is used as a trigger signal. At the right, an example of the resulting power spectral density functions is shown 


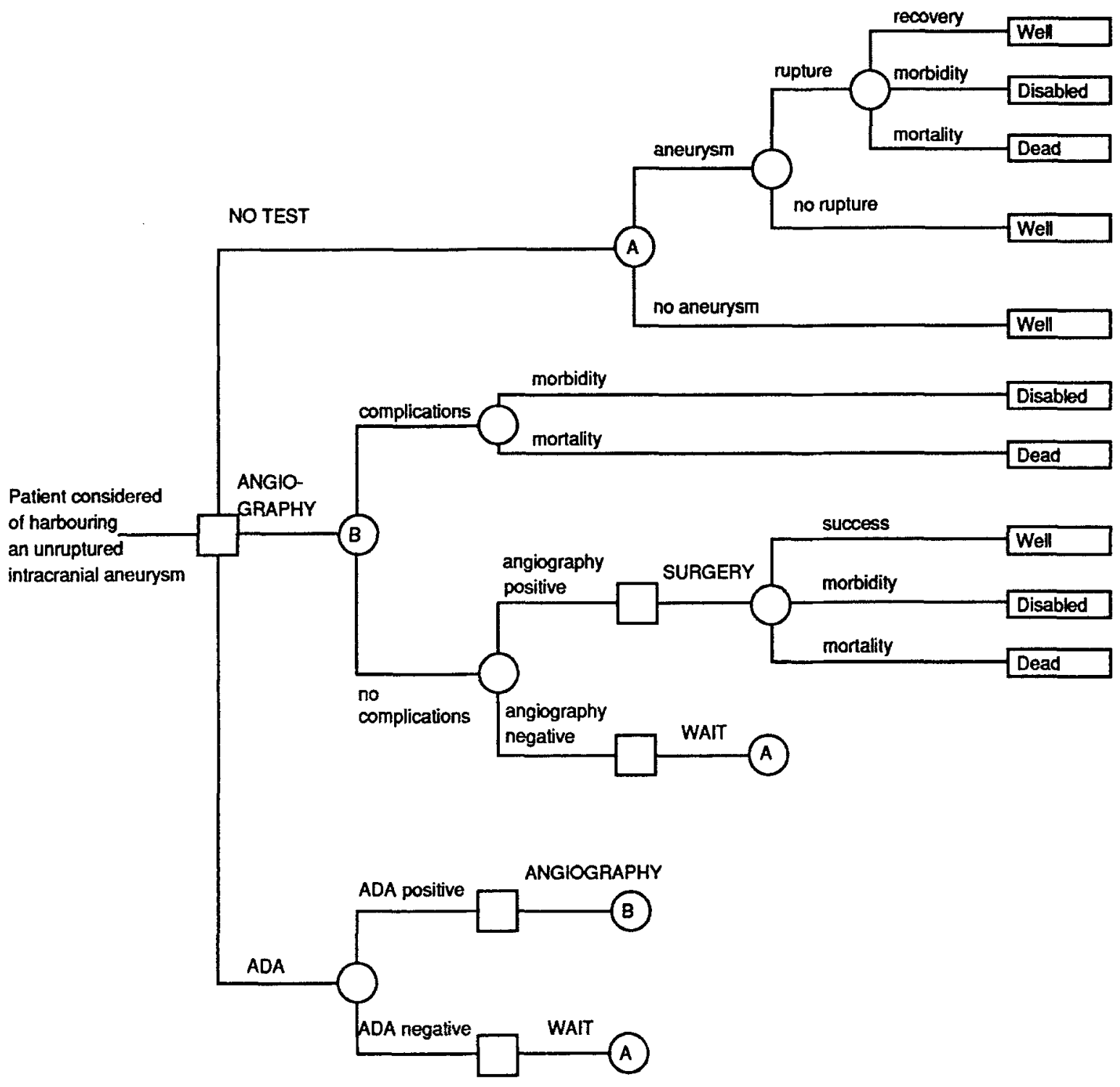

Fig. 2. Decision tree for the management of patients suspected of harbouring an unruptured intracranial aneurysm

regression models with linear and quadratic terms were considered. The models were evaluated using a log-likelihood ratio test and the crude error rate, i.e., the rate of patients that were misclassified [12].

\section{Decision Analysis}

A simple decision rule would advise action as if an aneurysm would be present when the post-test odds of an aneurysm would be larger than 1, and act as if an aneurysm would not be present when the post-test odds of an aneurysm would be smaller than 1 . These are called the diagnostic threshold odds.

The likelihood ratio, which represents the diagnostic information obtaimed from the results of acoustic detection, is computed by taking the ratio of the post-test odds $\mathrm{O}_{\mathrm{p}}$ and the prior odds $\mathrm{O}_{\mathrm{j}}$ :

$$
L R=O_{p} / O_{i}
$$

The lower the prior odds, the higher the LR must be to let the post-test odds meet the threshold odds. The likelihood ratio that, for a certain prior, leads to a certain threshold odds, is called the threshold likelihood ratio (TLR). We adjusted the TLR to the clinical situation (population prevalence) using age-adjusted prior odds of an intracranial aneurysm. The diagnostic threshold likelihood ratio should also be adjusted for the risk/benefit ratio of acoustic detection. When the benefit from surgically treating an aneurysmpatient is much higher than the loss from undergoing "unnecessary" angiography in a patient without an aneurysm, one would be inclined to choose a lower diagnostic threshold, in order to maximize the benefit from aneurysm detection. The lower the loss incurred by angiography compared to the benefit of aneurysm surgery, the lower the threshold likelihood ratio for an aneurysm might be at which angiography may be ordered, and the other way around.

The expected loss from "unnecessary" angiography was expressed in quality adjusted life years, and depended on the 
Table 1. Probabilities and Utilities Estimated for the Decision Tree Analysis of Angiography and Surgical Treatment of Unruptured Intracranial Aneurysms

\begin{tabular}{|c|c|c|}
\hline & $\begin{array}{l}\text { Point } \\
\text { estimate }\end{array}$ & Plausible range \\
\hline \multicolumn{3}{|l|}{ Prior probability of an unruptured IA $[6,18]$} \\
\hline age $0-10$ & $0.1 \%$ & $0.05 \%-0.2 \%$ \\
\hline age $11-20$ & $0.2 \%$ & $0.1 \%-0.5 \%$ \\
\hline age $21-30$ & $0.5 \%$ & $0.25 \%-1 \%$ \\
\hline age $31-40$ & $1 \%$ & $0.5 \%-2 \%$ \\
\hline age $41-50$ & $4 \%$ & $2 \%-8 \%$ \\
\hline age $51-60$ & $6 \%$ & $3 \%-12 \%$ \\
\hline age $61-70$ & $7.5 \%$ & $3 \%-15 \%$ \\
\hline age $71-80$ & $8 \%$ & $4 \%-16 \%$ \\
\hline Annual rate of aneurysm rupture $[9,13,35,36,38,39]$ & $1 \%$ & $0.5 \%-2 \%$ \\
\hline Mortality from rupture $[1,11,23,24]$ & $55 \%$ & $50 \%-60 \%$ \\
\hline Morbidity from rupture & $15 \%$ & $10 \%-20 \%$ \\
\hline \multicolumn{3}{|l|}{ Surgery $[7,10,14,22,24,40]$} \\
\hline Mortality & $2 \%$ & $1 \%-4 \%$ \\
\hline Morbidity & $6 \%$ & $4 \%-10 \%$ \\
\hline \multicolumn{3}{|l|}{ Angiography [6] } \\
\hline Sensitivity & $85 \%$ & $70 \%-99 \%$ \\
\hline Specificity & $100 \%$ & - \\
\hline Mortality & $0.025 \%$ & $0.01 \%-0.05 \%$ \\
\hline Permanent disability & $0.25 \%$ & $0.1 \%-0.5 \%$ \\
\hline Transient morbidity & $5 \%$ & $1 \%-10 \%$ \\
\hline Time loss from transient morbidity after angiography & 7 days & - \\
\hline Time loss from angiography & 3 days & - \\
\hline \multicolumn{3}{|l|}{ Utility considerations [32] } \\
\hline Utility of disability & 0.75 & $0.625-0.875$ \\
\hline Annual discount rate & $5 \%$ & $0 \%-10 \%$ \\
\hline
\end{tabular}

mortality from angiography, the risk of permanent morbidity and the value of living with permanent neurological disability, the risk of transient morbidity and the time spent with transient morbidity in days, and the time loss from angiography itself, as a function of the normal life expectancy.

The benefit of treating a patient with an aneurysm, who was correctly classified (by angiography) as harbouring an aneurysm, was determined by the difference $\triangle$ in expected utility between no surgical treatment $E U(W A I T)$ and surgical treatment $E U$ (SURGERY). This quantity has to be multiplied by the probability that angiography indeed would have shown the aneurysm, the sensitivity of angiography Se. (Angiography needs to be done in any patient considered to harbour an aneurysm, in order to locate the aneurysm and determine the neurosurgical technique and the test characteristics of angiography are assumed to be independend to those of ADA.)

$$
\Delta=[E U(S U R G E R Y)-E U(W A I T) \times S e .
$$

These expected utilities were again expressed in (discounted) quality adjusted life years, and they were determined by decision tree analysis. Figure 2 shows the decision tree. It is adapted from previous decision-analytic studies of screening for and therapeutic management of unruptured (familial) intracranial aneurysms [6, 32]. In the decision tree each strategy is described in an orderly way. Time flows from left to right. A square node represents the point in time where a decision must be made. Chance nodes (circles) represent events that cannot be influenced directly by the decision marker. Outcome nodes (rectangles) represent the health states that result from each chain of events and decisions. In NO TEST the aneurysm (if present) may rupture and cause SAH resulting in death, serious permanent neurological disability, or recovery. Compared to the calculations in the acutal analysis, the time aspect has been simplified in the decision tree representation. Subarachnoid haemorrhage, which may occur at any time in the future, has been collapsed into one branch. It is assumed that after a nonfatal SAH the aneurysm is clipped, completely preventing haemorrhage.

When angiography is uneventful and the presence of an intracranial aneurysm is confirmed, surgery may follow. Neurosurgical treatment may be uncomplicated and the patient will lead a normal life, without risk of SAH. Surgery may also lead to serious, permanent neurological disability, or even death. The probabilities and utilities have been estimated and described before [6] (Table 1). Outcomes are expressed in discounted quality adjusted life expectancy $[6,8]$. ADA may indicate the presence of an aneurysm, and the same sequence of events will follow as in the case when angiography was ordered directly. When ADA does not indicate an aneurysm, no specific action is assumed to follow.

\section{Results}

Highly significant differences in mean difference error (MDE) and power median (PM) were found 
Table 2. Results of the Acoustic Detection Procedure in Patients $(N=89)$ and Controls $(N=73)$

\begin{tabular}{lll}
\hline & Patients & Controls \\
\hline Power median & & \\
Median & 837 & $620^{\mathrm{a}}$ \\
P25-P75 & $719-896$ & $571-689$ \\
Range & $482-1122$ & $512-965$ \\
\hline Mean difference error & & \\
Median & 403 & $114^{\mathrm{a}}$ \\
P25-P75 & $169-655$ & $61-165$ \\
Range & $18-1842$ & $16-1198$ \\
\hline
\end{tabular}

${ }^{a}$ Test for equality of medians $p<0.0001$.

between cases and controls (Table 2). A scatterplot (Fig. 3) suggested that combining the information of the two measurements might enhance the diagnostic performance of ADA, because patients with high values for both PM and MDE seem to be at high risk of harbouring an aneurysm. Three linear logistic regression models were fitted to these data. These three models were all highly significant and did not differ much in discriminatory ability: 39,38 and 40 patients out of 162 were misclassified (Table 3 ). The dispersion of the data in Fig. 3 suggested a quadratic relation between the likelihood of harbouring an aneurysm and the PM and the MDE. The fourth quadratic
Table 4. Diagnostic Threshold Likelihood Ratio TLR as a Function of Prior Odds and Risk/Benefit Ratio, Rounded to the Nearest Integer

\begin{tabular}{rlll}
\hline Age & Prior odds & RB/ratio & TLR \\
\hline $0-10$ & $1: 1221$ & 0.028 & 42 \\
$11-20$ & $1: 488$ & 0.029 & 17 \\
$21-30$ & $1: 243$ & 0.032 & 9 \\
$31-40$ & $1: 121$ & 0.038 & 6 \\
$41-50$ & $1: 29$ & 0.048 & 2 \\
$51-60$ & $1: 19$ & 0.072 & 2 \\
$61-70$ & $1: 15$ & 0.159 & 3 \\
$71-80$ & $1: 14$ & -1.54 & - \\
\hline
\end{tabular}

model of Table 3 indeed performed better than the previous thress ( 34 patients misclassified, for an overall accuracy of $79 \%$ ). The fit of each model was determined by ordering the patients according to the predicted probability of harbouring an aneurysm, then dividing the patients in 4 equally sized groups, and comparing the expected number of aneurysms according to the model, and the observed number of aneurysm in the data (Table 3). Model IV als had the best fit.

Each solid line in Fig. 3 divides the cases in those who have a more than $50 \%\left(O_{p}>1\right)$ chance of harbouring an aneurysm and those who do not, according

Table 3. Results of the Logistic Regression Analysis

\begin{tabular}{|c|c|c|c|c|c|c|c|c|}
\hline A & \multicolumn{2}{|c|}{ Model I } & \multicolumn{2}{|c|}{ Model II } & \multicolumn{2}{|c|}{ Model III } & \multicolumn{2}{|c|}{ Model IV } \\
\hline Logistic equation & \multicolumn{2}{|c|}{$-1.4+0.6 \times \mathrm{MDE}$} & \multicolumn{2}{|c|}{$-10.5+1.5 \times \mathrm{PM}$} & \multicolumn{2}{|c|}{$\begin{array}{l}-9.3+1.2 \times \mathrm{PM}+ \\
0.3 \times \mathrm{MDE}\end{array}$} & \multicolumn{2}{|c|}{$\begin{array}{l}-2.8-1.8 \times \mathrm{MDE}+0.3 \times \mathrm{PM} \\
+0.4 \times \mathrm{PM} \times \mathrm{MDE}\end{array}$} \\
\hline LLR & \multicolumn{2}{|c|}{-41.3} & \multicolumn{2}{|c|}{-60.6} & \multicolumn{2}{|c|}{-63.9} & \multicolumn{2}{|c|}{-69.9} \\
\hline Improvement $\mathrm{X}^{2}$ & \multicolumn{2}{|c|}{-} & \multicolumn{2}{|c|}{-} & \multicolumn{2}{|c|}{$6.6, p=0.01$} & \multicolumn{2}{|c|}{$12.0, \mathrm{p}<0.001$} \\
\hline Errors FN/FP & \multicolumn{2}{|c|}{$28 / 10$} & \multicolumn{2}{|c|}{$21 / 18$} & \multicolumn{2}{|c|}{$17 / 23$} & \multicolumn{2}{|c|}{$30 / 4$} \\
\hline Error rate & \multicolumn{2}{|c|}{0.235} & \multicolumn{2}{|c|}{0.24} & \multicolumn{2}{|c|}{0.247} & \multicolumn{2}{|c|}{0.21} \\
\hline B & \multicolumn{2}{|c|}{ Model I } & \multicolumn{2}{|c|}{ Model II } & \multicolumn{2}{|c|}{ Model III } & \multicolumn{2}{|c|}{ Model IV } \\
\hline Group $1(\mathrm{~N}=40)$ & $\begin{array}{l}\text { expected } \\
12.6\end{array}$ & $\begin{array}{l}\text { observed } \\
14\end{array}$ & $\begin{array}{l}\text { expected } \\
8.1\end{array}$ & $\begin{array}{l}\text { observed } \\
11\end{array}$ & $\begin{array}{l}\text { expected } \\
8.8\end{array}$ & $\begin{array}{l}\text { observed } \\
12\end{array}$ & $\begin{array}{l}\text { expected } \\
10.9\end{array}$ & $\begin{array}{l}\text { observed } \\
10\end{array}$ \\
\hline Group $2(\mathrm{~N}=40)$ & 15.8 & 10 & 14.8 & 13 & 13.9 & 11 & 13.3 & 13 \\
\hline Group $3(\mathrm{~N}=40)$ & 23.3 & 28 & 28.2 & 25 & 27.5 & 26 & 24.2 & 26 \\
\hline Group $4(\mathrm{~N}=42)$ & 37.3 & 37 & 37.9 & 40 & 38.9 & 40 & 40.8 & 40 \\
\hline
\end{tabular}

A: Statistical significance, false negative and false positives, error rate. Legend: $P M$ power median of the power spectral density function, $M D E$ mean difference error of the normalized logarithmically transformed power spectral density function and a normal template, $L L R$ log likelihood ratio, $F N$ false negatives, $F P$ false positives.

B: Fit of the four logistic regression models. The fit is determined by sorting the subjects according to increasing predicted likelihood of harbouring an aneurysm according to the model, and dividing them in equally sized groups. For each regression model, the expected and observed number of cases per group is listed. 


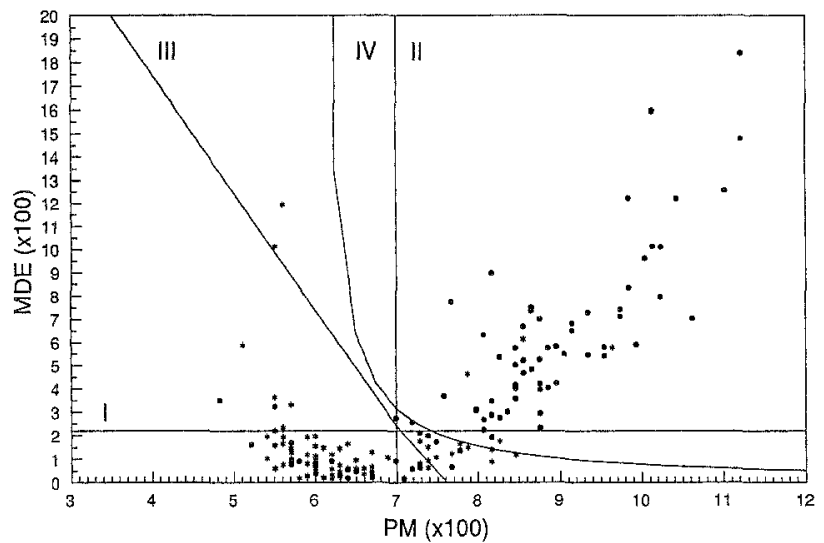

Fig. 3. Results of acoustic detection of aneurysms. X-axis; powermedian $(P M)$, Y-axis: mean difference error (MDE). Filled circles: controls ( $n=73$ ), asterisks: (cases $n=89$ ) and results of the logistic regression analyses: unadjusted diagnostic threshold likelihood ratios according to four logistic regression models (see Table 3). The lines represent unadjusted diagnostic threshold likelihood ratios that lead to post test odds for an intracranial aneurysm of 1 , according the four logistic regression models (I-IV)

to the regression models. However, as we argued in the methods section, this threshold may not be adequate for the application of ADA in clinical practice. Adjustment factors for the diagnostic threshold likelihood ratio are therefore suggested in Table 4, taking into account the population-based (age-dependent) prior odds of an intracranial aneurysm and the (agedependent) risk-benefit ratio related to angiography and surgical treatment. For patients in the age category between 41 and 60 , these two factors almost balance each other. This table lists the benefits or losses incurred when using the acoustic detection in patients without increased risk of harbouring an intracranial aneurysm. Angiography would lead to a small loss, and ADA would lead on average to a small benefit in patients aged less than 70 , especially in those aged between 41 and 60 .

\section{Discussion}

We evaluated an acoustic detection technique to be used in screening for unruptured intracranial aneurysms in a controlled study. Logistic regression analysis was used to determine the diagnostic accuracy and decision theory to establish indications for the use of acoustic detection in clinical practice.

Our results can be used in deciding whether the results of ADA in a certain patient warrant four-vessel cerebral angiography. For example, when a healthy 45-year-old man underwent screening with $\mathrm{ADA}$, the power median might be 700 , and the mean

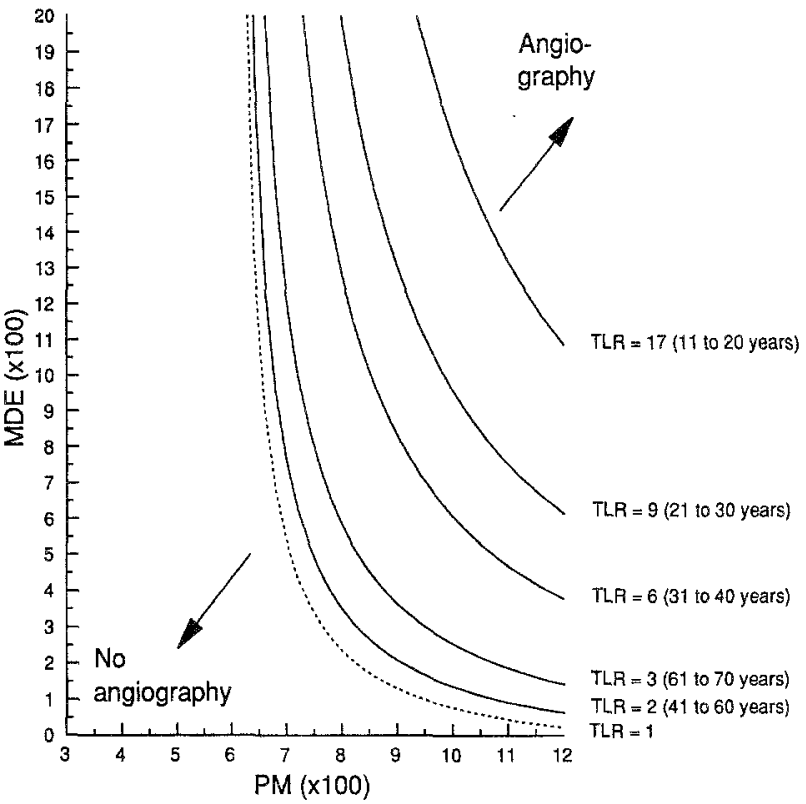

Fig. 4. Age-dependent threshold likelihood ratios of an intracranial aneurysm after the acoustic detection procedure, as a function of the mean difference error MDE (X-axis) and the power median PM ( $\mathrm{Y}$-axis). Above the lines and to the right, angiography is recommended, and below and to the left, no angiography

difference error 550, leading to a likelihood ratio of 1 , which does not exceed the threshold for ordering angiography (see Fig. 4). Therefore, these results would not justify recommending angiography to this patient. The situation would be different when PM would have been 800 and the MDE 500 in this patient. With such a test result, angiography would surely be warranted. When the patient would have an increased risk of harbouring an intracranial aneurysm, for example because he had a first degree family member with $\mathrm{SAH}$, this would lead to an approximate threefold increase in prior odds of harbouring an IA [4]. The TLR could then be adjusted downward to $1 / 3$ of its original value, and angiography should be recommended, according to this analysis. If the patient had been 75 years old, then aneurysm surgery could never be recommended because the risk/benefit ratio would be negative and angiography should not be performed (Table 4).

Table 5 shows that the population prevalence is lower than the probability that is minimally needed to justify angiography: the difference in expected utility between no testing and angiography is always negative, i.e., in favour of no testing. On average, a tiny amount of quality adjusted life expectancy will be gained by ADA, especially in the age group of $40-60$. 
Table 5. Comparison of the Results of Detection of Intracranial Aneurysms in Patients without Increased Risk with Angiography or the Acoustic Detection Device (ADA)

\begin{tabular}{|c|c|c|c|c|c|}
\hline Age & $\begin{array}{l}\text { Prior } \\
\text { probability }\end{array}$ & $\begin{array}{l}\text { Angiography } \\
\text { detected IA }\end{array}$ & $\delta$ EU1 & $\begin{array}{l}\text { ADA } \\
\text { detected IA }\end{array}$ & $\delta E U 2$ \\
\hline $0-10$ & $0.1 \%$ & $0.1 \%$ & -0.026 & $0.0 \%$ & 0 \\
\hline $11-20$ & $0.2 \%$ & $0.2 \%$ & -0.024 & $0.1 \%$ & 0 \\
\hline $21-30$ & $0.5 \%$ & $0.4 \%$ & -0.022 & $0.2 \%$ & 0.002 \\
\hline $31-40$ & $1.0 \%$ & $0.9 \%$ & -0.019 & $0.4 \%$ & 0.003 \\
\hline $41-50$ & $4.0 \%$ & $3.4 \%$ & -0.005 & $2.2 \%$ & 0.011 \\
\hline $51-60$ & $6.0 \%$ & $5.1 \%$ & -0.005 & $3.4 \%$ & $0.010-$ \\
\hline $61-70$ & $7.5 \%$ & $6.3 \%$ & 0.012 & $4.0 \%$ & 0.004 \\
\hline
\end{tabular}

Listed are the prior probability of an intracranial aneurysm as a function of age, the probability of being detected and operated on, and the difference in quality adjusted life expectancy between angiography and no testing ( $\delta E U 1)$ and between ADA and no testing ( $\delta E U 2)$.

This provides the rationale for detection of aneurysms with a non-invasive, riskless device such as ADA, in order to select patients for angiography.

In our study, control patients did not undergo angiography. Thus, it cannot be excluded that one or more control patients actually harboured an intracranial aneurysm. This is not such a great problem, because the prevalence of aneurysms in asymptomatic patients is just a few percent. The alternative would have been to let all control patients undergo angiography, thereby exposing them to unnecessary risks. Perhaps a future study confined to patients at high risk of harbouring an IA, angiography may be carried out prospectively, and independently to acoustic detection. Most cases were patients with ruptured aneurysms, who were studied before they were operated on. Rupture of the aneurysm, but also vasospasm may have changed the spectrum of intracranial sounds. Vasospasm was excluded by repeated transcranial doppler studies in our patients. The observer was not blind to the diagnosis, because of practical circumstances. However, as we used an objective measurement, the results could scarcely have been influenced by knowledge of the actual diagnosis. On the other hand, we did not consider the possibility that abnormal test results may also point at intracranial pathology other than aneurysms, such as meningiomas or other brain tumours, arteriovenous malformations, etc. In clinical practice, a false-positive result may thus have unexpected consequences, and perhaps even be advantageous to the patient.

MR-angiography seems to be developing into the preferred non-invasive detection procedure for intracranial aneurysms. MR-angiography is more expensive than ADA. Moreover, its sensitivity may be impaired because of superimposition of vessels (venous and arterial), a technical problem that is not yet solved. Clinicians and health care managers alike should not rest content with the fact that this technique has not yet been formally evaluated with regard to diagnostic accuracy and costs for detection of intracranial aneurysms.

The results of any decision analysis, particularly of the present one, should be considered as a recommendation, which is blinded to the details of the clinical situation. The judgment whether the recommendation should be followed depends on the treating physician. The management of the patient always remains the responsibility of the doctor, it is he or she who gathers and judges the clinical information and weighs the evidence. Perhaps the decision model should best be integrated with the software for sampling the sound frequencies in the acoustic detection device, so that the management recommendation could be produced alongside with the power spectral density functions and its derived measures, the PM and MDE.

To obtain reasonable certainty that ADA really is worthwhile from a clinical point of view, an independent study should be able to reproduce the results we presented here, and costs should also be taken into account. Such a study, in which MR angiography is also evaluated, is currently being carried out. The results of the present study suggest that acoustic detection has the potential of becoming a useful tool in the non-invasive diagnosis of occult, asymptomatic intracranial aneurysms.

\section{References}

1. Alvord EC, Loeser JD, Bailey WL, Copass MK (1972) Subarachnoid haemorrhage due to ruptured aneurysms. A simple method for estimating prognosis. Arch Neurol 27: 273-284

2. Bamford $\mathbf{J}$, Sandercock $P$, Dennis M, Burn J, Warlow CP 
(1990) A prospective study of acute cerebrovascular disease in the community: the Oxfordshire Community Stroke Project 1981-86 Part 2. Incidence, case fatality rates and overall outcome at one year of cerebral infarction, primary intracerebral and subarachnoid haemorrhage. J Neurol Neurosurg Psychiatry 53: $16-22$

3. Blatter DD, Parker DL, Ahn SS, Bahr AL, Robinson RO, Schwartz RB, Jolesz FA, Boyer RS (1992) Cerebral MR angiography with multiple overlapping thin slab acquisition. Radiology 183: 379-389

4. Bromberg JEC, Rinkel GJE, Algra A, Greebe P, Van Duyn CM, Hasan D, Limburg M, Ter Berg JWM, Wijdicks EFM, Van Gijn J (1995) Subarachnoid hemorrhage in first and second degree relatives of patients with subarachnoid hemorrhage. Brit Med J 311: 288-289

5. Chapman AB, Rubinstein D, Hughes R, Stears JC, Earnest MP, Johnson AM, Gabow PA, Kaehny WD (1992) Intracranial aneurysms in autosomal dominant polycystic kidney disease. $\mathrm{N}$ Engl J Med 327: 916-920

6. Dippel DWJ, Ter Berg JWM, Habbema JDF (1991) Screening for unruptured familial intracranial aneurysms. A decision analysis. Acta Neurol Scand 86: 381-389

7. Freger P, DeSousa MM, Sevrain L, Greissard P, Tadie M, Toumi K, Houtteville JP, Plas JY, Baumgartner J, Bernhard MA (1987) Faut-il opérer les aneurysmes asymptomatiques? A propos de 114 aneurysmes asymptomatiques opérés. Neurochirurgie 33: $462-468$

8. Habbema JDF, Bossuyt PMM, Dippel DWJ, Marshall S, Hilden J (1990) Analysing clinical decision analyses. Stat Med 9: 1229-1242

9. Heiskanen $O$ (1981) Risk of bleeding from unruptured aneurysms in cases with multiple intracranial aneurysms. J Neurosurg 55: 524-526

10. Heiskanen $O$ (1986) Risks of surgery for unruptured aneurysms. J Neurosurg 65: 451-453

11. Hijdra A, Braakman R, Van Gijn J, Vermeulen M, Van Crevel H (1987) Aneurysmal subarachnoid haemorrhage. Complications and outcome in a hospital population. Stroke 18: 1061-1067

12. Hilden J, Habbema JDF, Bjerregaard B (1987) The measurement of performance in probabilistic diagnosis. III. Methods bases on continuous functions of the diagnostic probabilities. Meth Inform Med 238-246

13. Jane JA, Kassell NF, Tomer JC, Winn HR (1985) The natural history of aneurysms and arteriovenous malformations. J Neurosurg 62: 321-323

14. Jomin M, Lesoin F, Lozes G, Fawaz A, Villete L (1987) Surgi$\mathrm{cal}$ prognosis of unruptured intracranial arterial aneurysms. Report of 50 cases. Acta Neurochir (Wien) 84: 85-88

15. Journee HL, Van Bruggen AC, Van der Meer JJ, De Jonge AB, Mooij JJ (1995) Design and application of sensor for recording sounds over human eye and nose. Med Biol Eng Comput 33: $140-144$

16. Kosugi Y, Goto T, Ikebe J, Joshita H, Takakura K (1983) Sonic detection of intracranial aneurysm and AVM. Stroke 14: $37-42$

17. Kosugi Y, Ikebe J, Hara S, Takakura K (1987) Detection and analysis of cranial bruit. IEEE Transact Biomed Eng 34: $185-191$

18. McCormick WF (1971) Problems and pathogenesis of intra- cranial arterial aneurysms. In: Toole JF, Moossy J, Janeway R (eds) Cerebral vascular disease, seventh conference. Grune \& Stratton, New York

19. Newell DW, LeRoux PD, Dacey RG, Stimac GK, Winn HR (1989) CT infusion scanning for the detection of cerebral aneurysms. J Neurosurg 71: 175-179

20. Olinger CP, Wasserman JF (1977) Electronic sthetoscope for detection of cerebral aneurysm, vasospasm and arterial disease. Surg Neurol 8: 298-312

21. Pernicone JR, Siebert JE, Potchen EJ, Pera A, Dumoulin CL, Souza SP (1990) Three-dimensional phase-contrast MR angiography in the head and neck: preliminary report. Am J Neuroradiol 11: 457-466

22. Pertuiset B, Mahdy M, Sichez JP, Arthuis F, Bitar A, Pertuiset BF, Harsa T, Bordi L (1991) Les aneurysmes arteriels sacculaires intracraniens non rumpus de l'adulte d'un diametre inferieur a $20 \mathrm{~mm}$. Chirurgie radicale dans 90 cas. Rev Neurol 147 : $111-120$

23. Phillips LH, Whisnant JP, O'Fallon WM, Sundt TM (1980) The unchanging pattern of subarachnoid hemorrhage in a community. Neurology 30: 1034-1040

24. Rice BJ, Peerless SJ, Drake CG (1990) Surgical treatment of unruptured aneurysms of the posterior circulation. $J$ Neurosurg 73: $165-173$

25. Richardson C, Kofman O (1951) Cranial bruit with intracranial saccular aneurysms. Trans Am Neurol Assoc 76: 151-154

26. Ross JS, Masaryk TJ, Modic MT, Ruggieri PM, Haacke EM, Selamn WR (1990) Intractanial aneurysms: evaluation by MR angiography. Am J Neuroradiol 11: 449-456

27. Schmid UD, Steiger HJ, Huber P (1987) Accuracy of high resolution computed tomography in direct diagnosis of cerebral aneurysms. Neuroradiology 29: 152-159

28. Sclabassi RJ, Sum M, Wasserman JF, Blue HB (1987) An acoustic aneurysm-detector. Med Instrum 21: $317-322$

29. Sekhar LN, Wasserman JF (1984) Noninvasive detection of intracranial vascular lesions during an electronic stethoscope. $J$ Neurosurg 60: 553-559

30. Torres VE, Wiebers DO. Forbes GS (1990) Cranial computed tomography and magnetic resonance imaging in autosomal dominant polycystic kidney disease. J Am Soc Nephrol 1: $84-90$

31. Van Bruggen AC, Mooij JJA, Journee HL (1991) The acoustic detection of intracranial aneurysms. Neurosurgery 29: 845-849

32. Van Crevel H, Habbema JDF, Braakman R (1986) Decision analysis of the management of incidental intracranial saccular aneurysms. Neurology 36: 1335-1339

33. Van Dooren BT, Van Bruggen AC, Mooij JJ, Hew JM, Journee HL (1994) Noisy intracranial tumours. Acta Neurochir (Wien) 131: 215-222

34. Whisnant JP, Phillips LH, Sundt TM (1982) Aneurysmal subarachnoid haemorrhage. Timing of surgery and mortality. Mayo Clin Proc 57: 471-475

35. Wiebers DO, Whisnant JP, O'Fallon WM (1983) The natural history of unruptured intracranial aneurysms. Neurosurgery 12: 291-297

36. Wiebers DO, Whisnant JP, Sundt TM, O'Fallon WM (1987) The significance of unruptured intracranial aneurysms. J Neurosurg 66: 23-29

37. Wiebers DO, Torres VE (1992) Screening for unruptured intra- 
cranial aneurysms in autosomal dominant polycystic kidney disease. N Engl J Med 327: 953-955

38. Winn HR, Taylor J, Kassell DL (1983) Prevalence of asymptomatic incidental aneurysms. Stroke 14: 121

39. Winn HR, Almaani WS, Berga SL, Jane JA, Richardson AE (1985) The long-term outcome in patients with multiple anenrysms. Incidence of late hemorthage and implications for treatment of incidental aneurysms. J Neurosurg 59: 642-651

40. Wirth FP, Laws ER, Piepgras D, Scott RM (1983) Surgical treatment of incidental intracranial aneurysms. Neurosurgery 12: $507-511$

\section{Comments}

The authors describe a method for acoustic detection of intracranial aneurysms with microphones applied to the patient's eyes. The accuracy of prediction of an intracranial aneurysm was $79 \%$. They conclude that this method could be a useful tool for the noninvasive diagnosis of occult, asymptomatic intracranial aneurysms.

It would be interesting in a future study to combine the acoustic method with MR-angiography even though more expensive, but also a non-invasive method for comparison of the acurracy of the prediction of an asymptomatic aneurysm. Maybe MR-angiography would be a second method after acoustic investigation in patients with doubtful results by the first method.

$$
\text { R. Seiler }
$$

Van Bruggen et al. previously described a technique for the acoustic detection of aneurysms (Neurosurgery 29: 845-849, 1991). In the current manuscript, they attempt to use data from this technique to decide whether angiography is indicated. Overall, the decision analysis is quite difficult to follow and the accuracy of the technique is unimpressive. The results describe highly significant differences in power median (PM) and the mean different error (MDE) values between aneurysm and control patients, but the overall diagnostic accuracy using the best decision methods is $79 \% ; 34$ of the 162 patients were misclassified. This is a low level of accuracy for a screening examination. Furthermore, according to their analysis, the gain in adjusted life expectancy by performing this test is minuscule $(0.01$ life years).

Adjustment factors for the diagnostic threshold likelihood ratio (TLR), specifically patient age, apparently make the technique more applicable clinically. However, when a technique which is based on the acoustics of turbulent flow in an aneurysm requires adjustment factors such as patient age and cannot stand on physical-anatomical properties alone, it becomes suspect.

Magnetic resonance angiography (MRA) has become the noninvasive diagnostic study of choice for unruptured intracranial aneurysms. This study is superior to acoustic detection techniques because it provides vascular anatomical data. In addition, MRA has diagnostic sensitivities and specificities around $90 \%$ and $90 \%$, respectively, for $5-\mathrm{mm}$ diameter aneurysms; these values increase with aneurysm size. One component lacking from the current paper is any discussion of aneurysm sizes in the 89 patients. As the authors note, MRA is indeed more expensive than acoustic detection studies. However, MRA at our institution costs \$ 500 and only an additional $\$ 200$ for an accompanying brain MR image scan. The authors do not describe the costs of their studies in the manuscript. Nonetheless, before neurosurgeons change their aneurysm screening practices, they must have data that demonstrate superior accuracy of acoustic detection over MRA at lower costs.

R. Spetzler and M. Lawton

Correspondence: Dr. D. W. J. Dippel, Department of Neurology, University Hospital Dijkzigt, Dr. Molewaterplein 40, NL-3015 GD Rotterdam, The Netherlands. 